\title{
Equivocation in Political Discourse: How Do We Know When It Is Happening?
}

\author{
Mohammed Alhuthali ${ }^{1}$ \\ ${ }^{1}$ Foreign Langauges Department, Faculty of Arts, Taif University, Saudi Arabia \\ Correspondence: Mohammed Alhuthali, Assistant Professor of Applied Linguistics, Foreign Langauges \\ Department, Faculty of Arts, Taif University, Taif 21944, Saudi Arabia. E-mail: \\ mohammed.alhuthali@gmail.com
}

Received: June 9, 2018 Accepted: July 26, 2018 Online Published: July 28, 2018

doi:10.5539/ijel.v8n6p69 URL: https://doi.org/10.5539/ijel.v8n6p69

\begin{abstract}
Equivocation is a mode of speech adopted when the speaker wishes to avoid a direct answer to a question but is unwilling to resort to telling a lie. The result is a mode of speech at least partly designed to obscure communication rather than achieve clarity. However, determining what is equivocation is complex, not least as it can show attributes close to that expected when making a nuanced argument that takes account of lack of information or current controversies about the issue. This suggests the equivocation is much a product of how a given speech is interpreted by the observer. This study takes an interview given by President Trump shortly after his inauguration in 2016. Each block of speech is coded for evidence of equivocation (and, if so, of the type of equivocation). The main finding was that he systematically used equivocation in the interview with the manner of this shifting a little as the focus of the interview changed. However, there was no correlation between his use of equivocation and those sections were other observers have suggested his answers were actually dishonest. The extent to which he uses equivocation as a normal part of speech calls into account earlier assumptions that politicians resort to this mode of discourse at particular times rather than as a standard response. In turn, this requires the observer to consider how they define equivocation and how they respond when a particular politician uses this approach.
\end{abstract}

Keywords: equivocation, interpretation, perception bias, President Trump, untruths

\section{Introduction}

\subsection{Equivocation in Discourse}

The idea that equivocation in speech has particular characteristics comes originally from very early work in Psychotherapy (Bavelas, Black, Chovil, \& Mullett, 1990; Bello, 2015; Lewin, 1939) where avoidance of a direct answer (Tracy \& Coupland, 1990) was one way in which a patient signalled distress and a desire to avoid choosing between unwelcome alternatives (such as not answering the question or having to directly address difficult thoughts and feelings). In Haley's original model (Haley, 1959) equivocation was thus a departure from the expectation that communication is designed to be clear between speaker (or writer) and the recipient. Bavelas et al. (1988) suggest that equivocation takes on a particular form of speech and can be identified as such. They developed a model (Bavelas, et al., 1990) that suggests equivocation occurs when the speaker departs from responding to a question using the format "I am saying this to you in this situation" (Bavelas et al., 1990, p. 137) that can be applied by the observer (or recipient) to any speech as a test of equivocation.

\subsection{The Purpose of Equivocation in Discourse}

The early work by Lewin (Lewin, 1939) tends to see equivocation as a flawed form of discourse designed to avoid addressing a difficult situation. This negative framing has been adopted in studies of political discourse where equivocation is seen as a tool used by politicians to avoid difficult questions (Vrij, 2008) and the concept is now often used to evaluate how politicians interact with interviewers (Clementson, 2016). However, other studies suggest that equivocation can be a successful tool to avoid conflict and to handle a difficult conversation with no loss of status or esteem (Williams \& Goss, 1975) attributed to the speaker. This in turn suggests that both identifying a pattern of speech as equivocation and whether this is seen as acceptable or unacceptable are judgements made by the observer as much as they are inherent to particular modes of discourse. 
Equivocation is seen as a form of speech that does not directly answer a question that has been posed. From this perspective, equivocation can be seen in terms of lack of clarity over one of the core elements in the communication process (Bavelas, Black, Bryson, \& Mullett, 1988). Thomas (1992) argues, following Lewin's original work (Lewin, 1939) that one reason for such lack of clarity is when the individual does not wish to answer the question as posed but realises they have no choice but to provide some form of answer. To the speaker the advantage of equivocation is it allows an escape from the (unwanted) consequences of clarity (Clementson, 2016). In a political context such evasion may be seen as an astute response and one that many modern politicians are coached to use so as to avoid directly telling a lie even if the response is deliberately unclear (Bavelas, et al., 1990) and the interpretation may be incorrect as the listener responds to the answer provided rather than the answer in the context of the original question.

In both its psychological and political setting, a common argument is that the use of equivocation is situational (Clementson, 2016) rather than "any intrinsic characteristic of the individual" (Bavelas et al., 1988, p. 137). In effect, the common assumption is not that someone answers every question with equivocation but instead that is a strategy deliberately chosen in a given situation.

This also suggests that the process of interpretation is situational to both speaker and observer/recipient. Depending on the circumstances the same response to a given question may elicit a very different response and may or may not be an instance of equivocation. So asking 'how are you' to a friend in a social situation may well elicit the perfectly accepted response of 'ok'. If the same question is posed by a doctor to a patient, it is quite likely that such a response would be seen as a form of equivocation and lead to further prompting by the doctor to understand what is meant by 'ok'. Thus both the wider situation, and our expectation of what is an acceptable response, have a role in determining how we interpret a particular comment. From this, a wider issue is whether or not a particular response is something we might expect to hear in response to a question in a particular set of circumstances.

\subsection{Equivocation and Dishonesty}

One further complication is the possible relationship between the usage of equivocation and actually telling untruths (W. P. Robinson, Shepherd, \& Heywood, 1998). In one group of experiments, lying was found to be related both to the likelihood of being detected and the importance of the response to the recipient. So individuals were more likely to lie about their ability to match key personal criteria on a job application than they were as a doctor telling a patient some bad news. Robinson et al (1998) note that in both instances, for most people, truth telling was by far the most common response and that telling a lie was related to the perceived importance of the truth to the recipient (William Peter Robinson, 1996). However, as with equivocation, lieing requires both the speaker to adopt that strategy and the observer to notice this. While, most of the time we would rather know what was true, there are three situations where the recipient may either not care, or not be prepared to find out. First is if the situation is trivial, second we fear the consequences if the truth emerges (such as damaging the reputation of someone we admire) and third that the recipient is unsure of how they will act if the truth emerges. All these tend to reduce any commitment to actually testing whether a given statement is a lie (Vrij, 2008).

The key difference to equivocation is that when using equivocation the speaker is seeking to avoid saying something they know to be untrue even if they are unwilling (or unable) to directly respond to the question. Thus an untrue response may not show any of the attributes of equivocation as it will directly engage with the question.

\subsection{Equivocation and Ambuguity}

A second complication is when the speaker is reflecting genuine ambiguity in their answer. This may lead to patterns of speech similar to equivocation in particular in terms of presenting the opinions of others as a possible answer. In this case the equivocation could be a genuine reflection that the speaker is not clear as to which is their preferred option. In many situations, when faced with such ambiguity, a decision maker will reframe the problem so one option becomes clearly more preferable (Montgomery, 2006) in others it may lead to caution and a careful search for better understanding (DeKay, Patiño-Echeverri, \& Fischbeck, 2009).

In consequence, when analysing speech for equivocation there is a need to consider two extra factors. First a dishonest answer may well not display the traits associated with equivocation and second some of the traits of equivocation maybe found in a response where the speaker is genuinely reflecting uncertainty or a lack of understanding of the options. 


\subsection{Characteristics of Equivocation in Speech}

Conventionally a key characteristic of equivocation (Haley, 1959) is that it breaks the expectation that a response will be clear on all of four elements. In Haley's model, the four elements were that: I (the sender) am saying this (the contents) to you (the receiver) in this situation (the context). In effect since equivocation breaks one or more of these requirements it is a "departure from essentials of clear communication" (Haley, 1959, p. 138). However, while Haley (1959) would see ambiguity in the context of the sender (i.e. if the sender uses the opinions of someone else) as indicative of communication flawed by equivocation, other methods of coding speech identify this as one means by which the speaker can offer a nuanced opinion showing an awareness that there are multiple perspectives (Martin \& White, 2005). In this case, the difference between presenting a complex, nuanced, argument and equivocation is subtle, but one suggestion is that the former still involves the speaker presenting their own viewpoint (however unsure they are) and the latter is the use of someone else's opinions as a proxy for their own.

Bavelas et al. (1988) adopted this four element model and suggested that the existence, and form, of any equivocation could be tested by asking the following questions of each of the four elements:

- Sender: How much is the message the speaker's own opinions?

- Content: How clear is the message in its own terms (in other words does the formulation make sense)?

- Receiver: How far is the message directly addressed to the immediate listener?

- Context: How much is the answer a direct response to the question?

In experiments, there was a clear increase in the use of equivocation when the choice was between two options with matching advantages and disadvantages compared to when one option was clearly superior (Bavelas, et al., 1988). This suggests that equivocation is a chosen course in particular situations rather than a default mode of communication.

\subsection{Equivocation and Poitical Discourse}

The focus on equivocation has increasingly shifted from work in psychoanalytic settings to studying the patterns of speech by politicians (Clementson, 2016; Johansson, 2006). The initial focus shared the original perspective from Lewin (1939) that equivocation was problematic as it broke from the expectation of clear speech designed to be properly understood by the audience. However, in practice, the ability to answer a question without necessarily dealing with the substance of the issue and without resorting untruths has become a key skill for many politicians (Clayman, 2017; Ekström, 2015). Against this background, equivocation can be seen as a key skill with the response of the listener conditioned not so much by the existence of equivocation but their predisposition towards the speaker. If the listener agrees with the politician, equivocation might be praised as a sign of deftness in handling questions. On the other hand, a hostile listener may see equivocation as further evidence of why they mistrust that particular politician.

This suggests that a valid model of studying equivocation is not just to apply a structured form of interrogation such as that developed by Bavelas et al. (1988) but also to require the observer to address issues such as why they personally feel a given statement or response is a form of equivocation and also whether this is seen as positive (conflict management or reflecting genuine uncertainty) or negative (evasion).

This study addresses this debate using an interview given by President Trump shortly after his inauguration as President in 2017. The interview is first analysed using a structured framework and then the issue of personal judgement taken into account.

The result emphasises the extent that judgements about equivocation are very dependent on the personal expectations of the observer. However, accepting this, it was also clear that President Trump equivocated consistently across the entire interview which breaks one of Bavelas et al.'s (1988) assumptions that equivocation is a strategy chosen in particular instances. Equally this study identifies the problem of what happens when speech crosses from equivocation to dishonesty and how this is reflected in the mode of discourse adopted.

\subsection{Hypotheses and Their Correspondence to Research Design}

This study works from the assumption that the researcher (or listener) is as much an interpreter of the meaning (or intent) of speech as the original speaker and the immediate audience (in this case the journalist interviewing the President). This suggests three technical goals in this research and the need to acknowledge the importance of the process of interpretation by the researcher. 
Formally this research tests the applicability of Bavelas et al.'s (1988) model of equivocation, asks whether the volume or style might vary according to the question and whether their core assumption that equivocation is a chosen response in particular situations (in other words is not the normal mode of discourse) can be sustained.

Since President Trump is often accused of dishonesty by observers, this also allows an exploration of the claim that dishonesty might evoke different patterns of speech to equivocation when the speaker is seekin to avoid directly being dishonest. Going beyond this, while the formal coding system provideds a structure for the presented judgement, the issue of how the researcher responds remains important.

\section{Method}

This study is based on a transcript of an interview between US President Donald Trump and David Muir a journalist for the US ABC network carried out on 25 January 2017 shortly after Trump's inauguration (ABC, 2017). This analysis used the supplied transcript from ABC. The focus was on the use of equivocation but the problem of dealing with lies came up (Vrij, 2008). President Trump, both as a candidate and in office, has been a polarising figure and one problem is the extent to which many observers believe he is often dishonest in his answers (Berghel, 2017; Jack, 2017). Other analyses of this interview have suggested that other observers (Berghel, 2017; Jack, 2017) suggest that President Trump was lying, his speech follows none of the patterns of the test for equivocation (Bavelas, et al., 1988). For this study, an answer that deals with the question - even if there are strong reasons for believing it to be false - is not treated as an instance of evasion. However, it does raise the issue identified in the literature review that a dishonest answer takes on a different form to one that evades a direct response and there is a risk of interpreting a careful, modulated, response not as reflecting uncertainty but displaying evasion.

The interview transcript was divided into 274 blocks. A block occurs as the speaker changes, as an indication of over-talking or where the same speaker (in this transcript always President Trump) moves onto a second part to an answer. In the transcript, President Trump has 137 blocks and of these 88 were coded as evasion.

The coding was done in stages. First sessions were identified as potentially being examples of evasion from reading the text. Once this initial attribution was made, each of the suspected instances of evasion and equivocation was coded according to the criteria suggested by Bavelas et al. (1988) to distinguish between:

- Is it the sender's own opinion;

- Is the response clear;

- Is it addressed to the listener (here we have assumed the audience is the journalist but this is a complex issue and discussed below); and,

- Does it directly answer the question

Applying these criteria created other problems. There are instances where one block of President Trump's response to a given question was not an example of equivocation but another block is. This shifting between the two modes was a common feature in the interview. In effect, not everything he says is in answer to the question.

\section{Results}

\subsection{Sections of the Interview}

The interview covered nine substantive areas (if the opening and concluding remarks are excluded). In the course of this President Trump made 133 blocks of comments (as defined by the transcript) with the length varying from single word answers or interjections up to complete paragraphs. One substantive area came up twice (President Trump's attitude towards the use of torture) as the first set of questions generated substantial digressions. Some segments were relatively briefly dealt with and others saw a long series of sub-questions and responses. The spread was: 
Table 1. President Trump's responses by question

\begin{tabular}{ll}
\hline Topic & Responses \\
\hline Electoral Fraud & 43 \\
Immigration Control & 4 \\
Mexico Wall & 10 \\
Obamacare & 12 \\
Refugees & 23 \\
Scope of the job & 3 \\
Torture & 14 \\
Second set of qustions about torture & 14 \\
Violence in the US & 10 \\
Grand Total & $\mathbf{1 3 3}$ \\
\hline
\end{tabular}

Note. 4 blocks are excluded as they were connected to the introductory or concluding remarks.

This leads to two hypotheses that are explored below. First is whether the amount of equivocation varies with the topic (and if so, why) and second is whether the style of equivocation varies. The issues of dishonesty and uncertainty rather than evasion are returned to in the summary rather than directly coded as part of the analysis.

\subsection{Coding of Equivocation}

Coding the statements was complex and cross-checked as the analysis was made. Using Bavelas et al.'s (1990), taxonomy, equivocation was broken down into four categories. Examples of what they describe as 'Sender' (i.e. not the speaker's own opinions) include statements such as 'people that were calling in they're saying, 'We agree with Mr. Trump. We agree'. They're very smart people' (in connection to the discussion about electoral fraud). In terms of Content (i.e. clarity of the statement), examples include:

'And he was laughing at the system because he knew all of those votes were going to him. You look at Philadelphia, you look at what's going on in Philadelphia. But take a look at the tape of Barack Obama who wrote me, by the way, a very beautiful letter in the drawer of the desk. Very beautiful. And I appreciate it. But look at what he said, it's on tape. Look at what he said about voting in Chicago eight years ago. It's not changed. It hasn't changed, believe me. Chicago, look what's going on in Chicago. It's only gotten worse. ' (again in the section about electoral fraud, this section was also coded for lack of response to the question).

In terms of the receiver (i.e. is the answer addressed to the immediate listener), an example is:

'As far as I'm concerned we have to fight fire with fire. Now, with that being said I'm going with General Mattis. I'm going with my secretary because I think Pompeo's gonna be phenomenal. I'm gonna go with what they say. But I have spoken as recently as 24 hours ago with people at the highest level of intelligence. And I asked them the question, "Does it work? Does torture work?" And the answer was, "Yes, absolutely."' (in the second section dealing with the issue of torture).

The final category of not providing an answer to the question can be typified by an answer to a question asking for a reassurance that no-one will be worse off if Obamacare was repealed leading to:

'Right now you have millions and millions and millions of people that are unhappy. It's too expensive and it's no good. And the governor of Minnesota who unfortunately had a very, very sad incident yesterday 'cause he's a very nice guy but a couple of months ago he said that the Affordable Care Act is no longer affordable.'

Each such block was coded at two levels. First whether or not the researcher could match the mode of response to one of Bavelas et al.'s (1988) modes of equivocation. If there was no such evidence that segment was coded as having 'no equivocation' where equivocation was identified, the segment was coded in that manner. Once equivocation was identified, a secondary code was entered identifying the particular approach used.

Thus the first level of analysis was the extent that each question block elicited equivocation. 
Table 2. Extent of equivocation by question

\begin{tabular}{llll}
\hline Topic & No Equivocation & Equivocation & Total \\
\hline Electoral Fraud & 18 & 25 & 43 \\
Immigration Control & 2 & 2 & 4 \\
Mexico Wall & 4 & 6 & 10 \\
Obamacare & 2 & 10 & 12 \\
Refugees & 4 & 19 & 23 \\
Scope of the job & 3 & & 3 \\
Torture & 4 & 10 & 14 \\
Second set of qustions about torture & 4 & 10 & 14 \\
Violence in the US & 4 & 6 & 10 \\
Grand Total & $\mathbf{4 5}$ & $\mathbf{8 8}$ & $\mathbf{1 3 3}$ \\
\hline
\end{tabular}

One thing that stands out immediately is the volume of equivocation used. In some sections such as discussing his wish to prevent refugees from certain countries reaching the US, over $80 \%$ of his statements can be described as some form of equivocation. In addition, 36 statements were coded as reflecting more than one type of equivocation (most often lack of clarity and not answering the question). This provides 134 different coding rules used to describe equivocation in the interview.

In terms of President Trump's response to questions about the scope of the job, he did not equivocate but in other segments $60-80 \%$ of his statements can be described as equivocation.

\subsection{Different Amount and Style of Equivocation by Section}

The next step was to consider if the style of equivocation varied according to the topic as:

Table 3. Type of equivocation by question

\begin{tabular}{|c|c|c|c|c|c|}
\hline \multirow[b]{2}{*}{ Topic } & \multicolumn{5}{|c|}{ Type of Equivocation } \\
\hline & Not Own opinion & Lack of Clarity & Not Addressed to listener & Not a Direct answer & Total \\
\hline Electoral Fraud & 5 & 15 & 3 & 19 & 42 \\
\hline Immigration Control & & 2 & & 1 & 3 \\
\hline Mexico Wall & 1 & 6 & & 3 & 10 \\
\hline Obamacare & 1 & 8 & & 6 & 15 \\
\hline Refugees & & 12 & 1 & 16 & 29 \\
\hline Scope of the job & & & & & 0 \\
\hline Torture & & 5 & & 8 & 13 \\
\hline Second set of qustions about torture & & 5 & 2 & 7 & 14 \\
\hline Violence in the US & & 4 & 1 & 3 & 8 \\
\hline Grand Total & 7 & 57 & 7 & 63 & 134 \\
\hline
\end{tabular}

This indicates that even in an interview full of equivocation, the topic of the question led to different responses. Citing others as his justification for his response was common in the discussion about electoral fraud where President Trump claimed a report supported his allegation that this had been widespread. However, his basic technique was common across the interview. The lack of clarity came from long rambling answers, that often brought in other issues, and did not deal with the question.

So when questioned about electoral fraud, part of his answers were about his electoral strategy (to target the votes needed in the US electoral college rather than the popular vote) and the first discussion about his willingness to authorise torture became a digression about how well received a speech he had made at the CIA had been. Equally lack of clarity and not providing a direct answer were often coupled as he both evaded a direct answer and shifted the focus of his response to a different topic.

\section{Discussion}

Other studies of President Trump's speech patterns (Bosker, 2017; Ledford, 2016; Ott, 2017) have tended to note his habit of using similar formulations relying on simple sentences, repetition and a tendency to deviate from the question. In addition, he rarely expresses any doubt in his own views and will only cite dissenting voices in order to dismiss them - on his own terms. This analysis suggests that he uses equivocation almost as a default mode of response but that there are some differences in how he equivocates depending on the topic. 
If we look at his responses to the topic of his claims about the prevalence of electoral fraud, this is the only area where he regularly presents the opinions of others (research done by the Pew Foundation) rather than answers in his own terms. Overall in this section $60 \%$ of his responses are some degree of equivocation as he sought to maintain his argument that this was a widespread issue despite other evidence to the contrary (Fogarty, Curtis, Gouzien, Kimball, \& Vorst, 2015). Other commentators have suggested that several answers he gave in this respect were dishonest (Solis, 2017) not least as at one stage in this section he denied having made some comments only to be reminded he had sent the tweets cited himself. Of interest, in relation to the earlier discussion about the possible difference between evasive speech and dishonest speech, there was no discernible difference (i.e. of less evasion) at this stage than elsewhere.

For the rest of the interview, President Trump mainly uses lack of clarity in response or a digression and not answering the question as his main modes for evasion. This fits with Bosker's (2017) analysis that this reflects a method of communication often used by President Trump.

Returning to the questions posed at the start, we can say that President Trump uses evasion as a common mode of speech and that there is limited evidence he adopts certain forms in certain situations. There is no evidence that at moments of suggested dishonesty that this speech is any less reliant on evasion, suggesting that he tends to use certain verbal forms almost regardless of the accuracy of the actual information being conveyed. While it is not a question that can ever be answered apart from as an informed opinion, there is no evidence that any of the instances described as evasion are actually situations where the speaker is genuinely reflecting uncertainty or a contested point of view among respected experts in a field.

The final question is one of perception bias. Williams and Goss (1975) suggest there are instances were equivocation is accepted by the audience. Their study suggested that it could be approved of in a situation where it led to conflict reduction by not pressing a possibly contentious issue. In the case of President Trump many of his supporters are deeply suspicious of the conventional media and would either not accept that he was being evasive (in other words see the original question as unfair) or accept the evasion as a necessary response to hostile questioning. Thus, we are left with the uncomfortable conclusion that what, to one observer, is evasion designed to avoid an awkward question is to another a valid response to unfair critcism. In this case, Bavelas et al.'s (1988) model can be seen to be reliable in identifying equivocation but offers no guidance as to whether a respondent would see this as justified or not.

Finally, the extent to which President Trump uses evasion calls into question the assumption of both Clementson (2016) and Bavelas et al. (1990) that evasion is a situational response used to deal with particular questions. If so, we would expect to find blocks where evasion was rarely used and in reality it is used in two-thirds of President Trump's individual responses and in almost every block of questions. This suggests one of three explanations. That the interview was unremittingly hostile, forcing the respondent to evade to limit the impact; that the questions chosen were particularly uncomfortable for the President; or, that President Trump habitually uses evasion in answering questions. Listening to the interview and reading the transcript provides no evidence that the interview was particularly hostile. The questions chosen mostly flow from the events that occurred towards the end of the election campaign or decisions made in the very early days of his Presidency. While they may have been uncomfortable for the President, there is no a-priori reason to believe they were unfairly selected. If so, that leaves the final explanation that on the evidence of this transcript, President Trump regularly uses evasion, undermining the original assumptions of Clementson (2016) and Bavelas et al. (1990) in this respect.

\section{References}

ABC. (2017, 25 January). ABC News anchor David Muir interviews President Trump. Retrieved 15 March, 2018, from

http://abcnews.go.com/Politics/transcript-abc-news-anchor-david-muir-interviews-president/story?id=45047 602

Bavelas, J. B., Black, A., Bryson, L., \& Mullett, J. (1988). Political Equivocation: A Situational Explanation. Journal of Language and Social Psychology, 7(2), 137-145. https://doi.org/10.1177/0261927X8800700204

Bavelas, J. B., Black, A., Chovil, N., \& Mullett, J. (1990). Truths, Lies, and Equivocations: The Effects of Conflicting Goals on Discourse. Journal of Language and Social Psychology, 9(1-2), 135-161. https://doi.org/10.1177/0261927X9091008

Bello, R. S. (2015). Equivocation. In C. R. Berger, M. E. Roloff, S. R. Wilson, J. P. Dillard, J. Caughlin, \& D. Solomon (Eds.), The International Encyclopedia of Interpersonal Communication. London: John Wiley and Sons. https://doi.org/10.1002/9781118540190.wbeic226 
Berghel, H. (2017). Lies, damn lies, and fake news. Computer, 50(2), 80-85. https://doi.org/10.1109/MC.2017.56

Bosker, H. R. (2017). The role of temporal amplitude modulations in the political arena: Hillary Clinton vs. Donald Trump. Paper presented at the Interspeech 2017. https://doi.org/10.21437/Interspeech.2017-142

Clayman, S. E. (2017). The Micropolitics of Legitimacy: Political Positioning and Journalistic Scrutiny at the Boundary of the Mainstream. Social Psychology Quarterly, 80(1), 41-64. https://doi.org/10.1177/0190272516667705

Clementson, D. E. (2016). Why Do We Think Politicians Are So Evasive? Insight From Theories of Equivocation and Deception, With a Content Analysis of U.S. Presidential Debates, 1996-2012. Journal of Language and Social Psychology, 35(3), 247-267. https://doi.org/10.1177/0261927X15600732

DeKay, M. L., Patiño-Echeverri, D., \& Fischbeck, P. S. (2009). Better safe than sorry: Precautionary reasoning and implied dominance in risky decisions. Journal of Behavioral Decision Making, 22(3), 338-361. https://doi.org/10.1002/bdm.630

Ekström, M. (2015). Political Interviews. In K. Tracy, T Sandel, \& C. Ilie (Eds.), The International Encyclopedia of Language and Social Interaction (Vol. 3, pp. 1174-1176). https://doi.org/10.1002/9781118611463.wbielsi050

Fogarty, B. J., Curtis, J., Gouzien, P. F., Kimball, D. C., \& Vorst, E. C. (2015). News attention to voter fraud in the 2008 and 2012 US elections. Research \& Politics, 2(2), 2053168015587156. https://doi.org/10.1177/2053168015587156

Haley, J. (1959). An Interactional Description of Schizophrenia. Psychiatry, 22(4), 321-332. https://doi.org/10.1080/00332747.1959.11023187

Jack, C. (2017). Lexicon of Lies: Terms for Problematic Information. Data \& Society, 3.

Johansson, M. (2006). Constructing objects of discourse in the broadcast political interview. Journal of Pragmatics, 38(2), 216-229. https://doi.org/10.1016/j.pragma.2005.06.016

Ledford, H. (2016). Trump's immigration stance stokes fears for science: rhetoric in US presidential campaign concerns researchers--particularly Muslims. Nature, 532(7597), 13-15. https://doi.org/10.1038/532013a

Lewin, K. (1939). Field theory and experiment in social psychology: Concepts and methods. American Journal of Sociology, 44(6), 868-896. https://doi.org/10.1086/218177

Martin, J. R., \& White, P. R. R. (2005). The Language of Evaluation: Appraisal in English. Basingstoke, England: Palgrave Macmillan. https://doi.org/10.1057/9780230511910

Montgomery, H. (2006). Decision Making and Action: The Search for a dominance structure. In S. Lichtenstein \& P. Slovic (Eds.), The Construction of Preference (pp. 342-355). Cambridge: Cambridge University Press. https://doi.org/10.1017/CBO9780511618031.019

Ott, B. L. (2017). The Age of Twitter: Donald J. Trump and the politics of debasement. Critical Studies in Media Communication, 34(1), 59-68. https://doi.org/10.1080/15295036.2016.1266686

Robinson, W. P. (1996). Deceit, delusion, and detection. New York: Sage Publications.

Robinson, W. P., Shepherd, A., \& Heywood, J. (1998). Truth, Equivocation Concealment, and Lies in Job Applications and Doctor-Patient Communication. Journal of Language and Social Psychology, 17(2), 149-164. https://doi.org/10.1177/0261927X980172001

Solis, S. (2017, 26 January). In first TV interview, Donald Trump repeats unverified voter fraud, inaugural claims. https://www.usatoday.com/story/news/politics/onpolitics/2017/01/26/president-trump-abc-interview-davidmuir/97069516/

Thomas, K. W. (1992). Conflict and conflict management: Reflections and update. Journal of organizational behavior, 13(3), 265-274. https://doi.org/10.1002/job.4030130307

Tracy, K., \& Coupland, N. (1990). Multiple Goals in Discourse: An Overview of Issues. In K. Tracy \& N. Coupland (Eds.), Multiple Goals in Discourse (pp. 1-14). Bristol: Channel View Publications Ltd. https://doi.org/10.1177/0261927X9091001

Vrij, A. (2008). Detecting Lies and Deceit: Pitfalls and Opportunities. Chichester: John Wiley.

Williams, M. L., \& Goss, B. (1975). Equivocation: Character Insurance. Human Communication Research, 1(3), 
265-270. https://doi.org/10.1111/j.1468-2958.1975.tb00273.x

\section{Copyrights}

Copyright for this article is retained by the author(s), with first publication rights granted to the journal.

This is an open-access article distributed under the terms and conditions of the Creative Commons Attribution license (http://creativecommons.org/licenses/by/4.0/). 